\title{
Psychiatric problems in the first year after mastectomy
}

\author{
G P MAGUIRE, E G LEE, D J BEVINGTON, C S KÜCHEMANN, R J CRABTREE, C E CORNELL
}

British Medical fournal, 1978, 1, 963-965

\section{Summary and conclusions}

The psychiatric morbidity associated with mastectomy was assessed in 75 women by following them up from the time they presented with suspected breast cancer to one year after the operation. Fifty women with benign breast disease served as controls. Throughout the follow-up period the incidence of psychiatric problems was higher among the women who had undergone mastectomy. One year after surgery $19(25 \%)$ of these women compared with only $5(10 \%)$ of the controls needed treatment for anxiety or depression or both, and $16(33 \%)$ compared with $3(8 \%)$ respectively had moderate or severe sexual difficulties. Altogether 29 patients in the mastectomy group $(39 \%)$ and six of the controls $(12 \%)$ had serious anxiety, depression, or sexual difficulties. Of the eight women in the mastectomy group who sought help for their problems, only two felt that the help given had been appropriate.

The inability to recognise and treat these emotional

University Department of Psychiatry, Warneford Hospital, Oxford OX3 7JX

G P MAGUIRE, MRCPSYCH, clinical tutor in psychiatry (now senior lecturer, Department of Psychiatry, University Hospital of South Manchester, West Didsbury, Manchester M20 8LR)

D J BEVINGTON, MRCPSYCH, senior registrar (now consultant psychiatrist, Shelton Hospital, Shrewsbury)

C S KÜCHEMANN, BSC, research officer (now senior research officer, Cancer Information Association Advice Centre, Oxford)

R J CRABTREE, BSC, formerly research assistant

C E CORNELL, SRN, formerly research assistant

Radcliffe Infirmary, Oxford

E G LEE, FRCS, consultant surgeon disturbances is a common and serious problem. Monitoring by specially trained nurses and social workers might help to identify them earlier and even reduce them.

\section{Introduction}

Despite claims that mastectomy may cause serious psychological problems there has been little systematic study of the emotional and social consequences. ${ }^{1-4}$ We therefore sought to determine how mastectomy affects women with breast cancer, and particularly to establish the incidence of psychiatric morbidity in the first year after operation. Women with benign breast disease served as controls.

\section{Patients and methods}

INITIAL SAMPLE

Consecutive patients attending a breast clinic at the Radcliffe Infirmary, Oxford, were included in the study if they were to undergo breast biopsy for suspected cancer. A one-in-five sample was taken of the remaining attenders. Altogether 179 women were so obtained. A further 22 women were similarly recruited from the Royal Berkshire Hospital, Reading, and the Princess Margaret Hospital, Swindon. Before leaving the clinic each woman was seen by a research worker. The purpose of the study was explained and an arrangement made to interview her at home within a few days. Twenty-six women who could not be interviewed before admission were seen soon after discharge.

Assessments were conducted by interviewers who had received three months' training in the use of semi-structured questionnaires, psychiatric rating scales, and a life events schedule. Training consisted in practice interviews, which were tape-recorded and followed by discussion of the techniques used and ratings made.

Psychiatric ratings-A series of four-point scales (0-3) was used to rate the frequency and extent of key psychiatric symptoms. A rating of 0 or 1 indicated that symptoms were absent or slight (minor); a 
rating of 2 indicated morbid and clinically important symptoms (moderate); and a score of 3 was given when symptoms were persistent and severe (severe).

Initial interviews-During the initial home interview before biopsy the interviewers asked about anxiety, depression, and sexual problems during a specific period. When the women had discovered their breast disease within six months of seeing the surgeon, this period extended from three months before discovery up to the initial interview. When the delay was over six months symptoms were assessed from three months before medical advice had been sought. The Brown-Birley schedule $^{\tilde{j}}$ was used to determine whether any other stressful events had occurred in the year before attendance at the clinic, for such events may lead to psychiatric morbidity. ${ }^{6}$

Subsequent assessments-Women who underwent mastectomy were reinterviewed four months and one year after surgery to assess the incidence and duration of psychiatric symptoms, sexual problems, and other stressful events. The controls were similarly assessed at equivalent times. All interviews were tape-recorded so they could be checked and rated independently.

\section{FINAL SAMPLE}

Of the 201 women included in the study, 117 were found to have breast cancer. Ninety-six were reinterviewed four months and one year after mastectomy. Of the remainder, seven had died, three were too ill, four had moved house, and seven refused to be interviewed. Eighty of the 84 women with benign breast disease were similarly reassessed. As the mastectomy and control groups differed in age and marital status, and breast cancer had recurred in some patients, a subsample was taken. This comprised 75 women who were aged 65 or less and free of recurrent or advanced disease at follow-up. Fifty women who matched those in the mastectomy sample for age, social class, and marital status were selected at random from the control group.

\section{Results}

Mood disturbance before surgery-After discovering breast disease or seeking medical advice there was a sharp increase in the incidence of anxiety symptoms in both groups (table I). While the control group experienced less anxiety after visiting the clinic, anxiety increased among those who were to have a mastectomy. Twenty of these women $(27 \%)$ had moderate or severe anxiety-namely, persistent tension, inability to relax, headaches, sweating, palpitations, and panic attacks -before admission for biopsy. Discovery of breast disease had less effect on the incidence of depressive symptoms (table I). Even so, 23 patients in the mastectomy group $(31 \%$ ) suffered from moderate or severe anxiety and depression or both in the interval before biopsy because they feared that they had cancer and might lose a breast.

Mood disturbance after surgery-A higher incidence of both anxiety and depressive symptoms (table II) was found at follow-up in the women who had had mastectomy. One year after surgery symptoms of anxiety and depression or both were moderate in 13 of the women who had had mastectomy and severe in six, giving a combined incidence of $25 \%$. Only five control patients $(10 \%)$ had any such mood disturbance.

Duration-Any moderate or severe mood disturbance that occurred
TABLE II-Incidence of symptoms of anxiety and depression in 75 women four months and one year after mastectomy and in 50 contruls with benign breast disease assessed at equivalent times

\begin{tabular}{|c|c|c|c|c|c|c|c|c|}
\hline \multirow{3}{*}{$\begin{array}{l}\text { Classification of } \\
\text { symptoms }\end{array}$} & \multicolumn{4}{|c|}{ Four months* } & \multicolumn{4}{|c|}{ One year ${ }^{+}$} \\
\hline & \multicolumn{2}{|c|}{$\begin{array}{l}\text { Mastectomy } \\
\text { group }\end{array}$} & \multicolumn{2}{|c|}{ Controls } & \multicolumn{2}{|c|}{$\begin{array}{l}\text { Mastectomy } \\
\text { group }\end{array}$} & \multicolumn{2}{|c|}{ Controls } \\
\hline & No & $\because$ & No & ${ }_{\circ}^{\circ}$ & No & ${ }^{\circ} \circ$ & No & $\%$ \\
\hline \multicolumn{9}{|c|}{ Anxiety } \\
\hline None & 32 & 43 & 34 & 68 & 28 & 37 & 32 & 64 \\
\hline & 27 & 36 & 12 & 24 & 33 & 44 & 14 & 28 \\
\hline Moderate & 14 & 18 & 4 & 8 & 12 & 16 & 4 & 8 \\
\hline Severe & 2 & 3 & & & 2 & 3 & & \\
\hline \multicolumn{9}{|c|}{ Depression } \\
\hline None & 31 & 41 & 32 & 64 & 31 & 41 & 35 & 70 \\
\hline Minor & 24 & 32 & 12 & 24 & 28 & 38 & 11 & 22 \\
\hline Moderate & 19 & 26 & 6 & 12 & 11 & 15 & 4 & 8 \\
\hline Severe & 1 & 1 & & & 5 & 6 & & \\
\hline
\end{tabular}

* Comparison between mastectcmy and control groups for none $v$ some symptoms of anxiety at four months: $x^{2}=6.7 ; \mathrm{DF}=1 ; \mathrm{P}<0.01$; for none $v$ some symptoms of depression: $\chi^{2}=5 \cdot 3 ; \mathrm{DF}=1 ; \mathrm{P}<0.05$

+Comparison between mastectomy and control groups for none $v$ some symptoms of anxiety at one year: $x^{2}=7.5 ; \mathrm{DF}=1 ; \mathrm{P}<0.01$; for none $v$ some symptoms of depression: $\chi^{2}=8 \cdot 8 ; P<0.01$.

between discovering disease or seeking medical advice and the oneyear follow-up was categorised as short-term (lasting up to two months), medium-term (two to eight months), long-term (over eight months), or late (onset after four months' follow-up and present at one year). A total of $25(33 \%)$ of the women who had had mastectomy experienced anxiety reactions of varying duration. These were medium-term in nine $(12 \%)$, long-term in $13(17 \%)$, or late in three $(4 \%)$. Far fewer women $(5(10 \%))$ in the control group had done so $\left(\chi^{2}=7.7 ; \mathrm{DF}=1 ; \mathrm{P}<0.01\right)$. A similar proportion of patients in the mastectomy group $(26(35 \%))$ had suffered medium-term $(8(11 \%))$, long-term $(15(20 \%))$, or late $(3(4 \%))$ depressive reactions, compared with only $\operatorname{six}(12 \%)$ in the control group $\left(\gamma^{2}=6.9 ; \mathrm{DF}=1 ; \mathrm{P}<0.01\right)$.

Sexual problems were uncommon before discovery of the breast trouble or seeking medical advice in 48 women in the mastectomy group and 36 of the controls who still had a regular sex life. After mastectomy appreciable differences were evident (table III). One year after surgery, a third of the women who had had mastectomy had severe or moderate sexual problems. They had either stopped intercourse or ceased to enjoy it. In eight of these patients $(18 \%)$ sexual problems were medium-term and in $18(38 \%)$ long-term, giving a combined incidence of $56 \%$. Only three of the controls $(8 \%)$ had symptoms of such duration $\left(\gamma^{2}=17 \cdot 1 ; \mathrm{DF}=1 ; \mathrm{P}<0.001\right)$.

Overall morbidity-One year after surgery 29 women who had undergone mastectomy $(39 \%)$ had mood disturbance and sexual problems or both serious enough (moderate and severe) to warrant psychiatric help (table IV). Only six controls (12\%) had psychiatric or sexual problems, and all were moderate $\left(\chi^{2}=9 \cdot 3 ; \mathrm{DF}=1 ; \mathrm{P}<0.01\right)$. There was no difference between the two groups in the incidence of other stressful events or of previous psychiatric morbidity. So the greater morbidity in the mastectomy group could not be attributed to either of these factors.

Help given-Only eight of the 19 women needing psychiatric treatment for anxiety or depression had consulted their general practitioners. Six of these complained that their doctor's only response

TABLE I-Incidence of symptoms of anxiety and depression in 75 women requiring mastectomy for breast cancer and 50 controls with benign breast disease before and after discovering disease or seeking medical advice and after attending clinic

\begin{tabular}{|c|c|c|c|c|c|c|c|c|c|c|c|c|}
\hline \multirow{3}{*}{$\begin{array}{l}\text { Classification of } \\
\text { symptoms }\end{array}$} & \multicolumn{4}{|c|}{ Before discovery or seeking advice } & \multicolumn{4}{|c|}{ After discovery or seeking advice } & \multicolumn{4}{|c|}{ After attending clinic* } \\
\hline & \multicolumn{2}{|c|}{ Mastectomy group } & \multicolumn{2}{|c|}{ Controls } & \multicolumn{2}{|c|}{ Mastectomy group } & \multicolumn{2}{|c|}{ Controls } & \multicolumn{2}{|c|}{ Mastectomy group } & \multicolumn{2}{|c|}{ Controls } \\
\hline & No & $\%$ & No & $\%$ & No & $\%$ & No & $\%$ & No & $\%$ & No & ${ }_{0}^{\circ}$ \\
\hline \multicolumn{13}{|c|}{ Anxiety } \\
\hline $\begin{array}{c}\text { None } \\
\text { Minor } \\
\text { Moderate } \\
\text { Severe }\end{array}$ & $\begin{array}{r}50 \\
17 \\
8\end{array}$ & $\begin{array}{l}67 \\
23 \\
10\end{array}$ & $\begin{array}{r}32 \\
13 \\
5\end{array}$ & $\begin{array}{l}64 \\
26 \\
10\end{array}$ & $\begin{array}{r}19 \\
39 \\
15 \\
2\end{array}$ & $\begin{array}{r}25 \\
52 \\
20 \\
3\end{array}$ & $\begin{array}{r}13 \\
24 \\
11 \\
2\end{array}$ & $\begin{array}{r}26 \\
48 \\
22 \\
4\end{array}$ & $\begin{array}{r}18 \\
37 \\
18 \\
2\end{array}$ & $\begin{array}{r}24 \\
49 \\
24 \\
3\end{array}$ & $\begin{array}{r}22 \\
21 \\
6 \\
1\end{array}$ & $\begin{array}{r}44 \\
42 \\
12 \\
2\end{array}$ \\
\hline \multicolumn{13}{|c|}{ Depression } \\
\hline $\begin{array}{c}\text { None } \\
\text { Minor } \\
\text { Moderate } \\
\text { Severe }\end{array}$ & $\begin{array}{r}51 \\
20 \\
3 \\
1\end{array}$ & $\begin{array}{r}68 \\
27 \\
4 \\
1\end{array}$ & $\begin{array}{r}31 \\
13 \\
6\end{array}$ & $\begin{array}{l}62 \\
26 \\
12\end{array}$ & $\begin{array}{r}34 \\
31 \\
9 \\
1\end{array}$ & $\begin{array}{r}45 \\
41 \\
12 \\
1\end{array}$ & $\begin{array}{r}21 \\
23 \\
4 \\
2\end{array}$ & $\begin{array}{r}42 \\
46 \\
8 \\
4\end{array}$ & $\begin{array}{r}29 \\
34 \\
11 \\
1\end{array}$ & $\begin{array}{r}39 \\
45 \\
15 \\
1\end{array}$ & $\begin{array}{r}24 \\
19 \\
7\end{array}$ & $\begin{array}{l}48 \\
38 \\
14\end{array}$ \\
\hline
\end{tabular}

*Comparison between mastectomy and control group for none $v$ some symptoms of anxiety after attending clinic: $\chi^{2}$ (with Yates's correction) $=4 \cdot 6$; $\mathrm{P}<0.05$. 
TABLE III-Sexual problems in 48 women before discovering breast disease or seeking medical advice and four months and one year after mastectomy compared with 36 controls with benign breast disease assessed at equivalent times*

\begin{tabular}{|c|c|c|c|c|c|c|c|c|c|c|c|c|}
\hline \multirow{3}{*}{ Sexual problems } & \multicolumn{4}{|c|}{ Before discovery or seeking advice } & \multicolumn{4}{|c|}{ Four months after mastectomy ${ }^{+}$} & \multicolumn{4}{|c|}{ One year after mastectomy ${ }_{+}^{+}$} \\
\hline & \multicolumn{2}{|c|}{ Mastectomy group } & \multicolumn{2}{|c|}{ Controls } & \multicolumn{2}{|c|}{ Mastectomy group } & \multicolumn{2}{|c|}{ Controls } & \multicolumn{2}{|c|}{ Mastectomy group } & \multicolumn{2}{|c|}{ Controls } \\
\hline & No & $"$. & No & $"$. & No & $"$. & No & $"$ " & No & 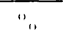 & No & $u_{0}$ \\
\hline $\begin{array}{c}\text { None } \\
\text { Minor } \\
\text { Moderate } \\
\text { Severe }\end{array}$ & $\begin{array}{r}40 \\
4 \\
3 \\
1\end{array}$ & $\begin{array}{r}84 \\
8 \\
6 \\
2\end{array}$ & $\begin{array}{r}26 \\
7 \\
3\end{array}$ & $\begin{array}{r}72 \\
20 \\
8\end{array}$ & $\begin{array}{r}25 \\
4 \\
6 \\
13\end{array}$ & $\begin{array}{r}52 \\
8 \\
13 \\
27\end{array}$ & $\begin{array}{r}27 \\
5 \\
2 \\
2\end{array}$ & $\begin{array}{r}75 \\
13 \\
6 \\
6\end{array}$ & $\begin{array}{r}26 \\
6 \\
11 \\
5\end{array}$ & $\begin{array}{l}54 \\
13 \\
23 \\
10\end{array}$ & $\begin{array}{r}28 \\
5 \\
1 \\
2\end{array}$ & $\begin{array}{r}78 \\
14 \\
2 \\
6\end{array}$ \\
\hline
\end{tabular}

*Twenty-seven and 14 patients from mastectomy and control groups respectively were excluded because regular sexual activity had ceased or information was not available. +Comparison between mastectomy and control groups for none $v$ some sexual problems at four months: $\chi^{2}=3 \cdot 66 ;$ DF $:=1 ;$ NS; for moderate or severe problems: $\chi^{2}=7 \cdot 0$; $\mathrm{DF}=1 ; \mathrm{P}<0.01$.

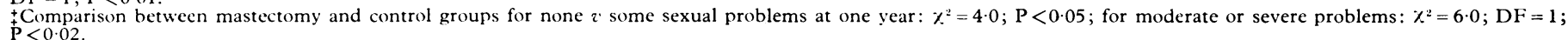

TABLE IV-Number of women with moderate and severe mood disturbances or sexual problems (or both) one year after mastectomy

Anxiety, depression, and sexual problems Anxiety and depression Depression and sexual problems Anxiety:

Sexual problemis

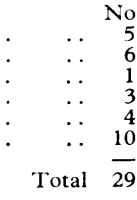

was to prescribe tranquillisers, usually low doses of anxiolytic drugs. None of the 10 women who developed sexual problems alone had sought help. Consequently, many of the women who had undergone mastectomy seemed to be paying a high price emotionally for the possibility of physical survival.

\section{Discussion}

Our findings confirm the existence of a high psychiatric morbidity in the first year after mastectomy for breast cancer. ${ }^{\text {? }}$ This should not be surprising, as identical problems occur after other mutilating surgery for cancer. ${ }^{\circledR}$ Moreover, the threats which each woman faces-namely, the possible loss of her femininity, self-esteem, health, role, and life-are known to cause psychiatric illness. ${ }^{9}$ Sixty-nine of the mastectomy group had had a simple or modified radical mastectomy. Only six had had a more radical procedure. So it is possible that radical mastectomy might lead to even greater morbidity than was found here. Radiotherapy may have contributed to the psychiatric morbidity in 62 of the women who had had mastectomy. They said that it made them feel exhausted and even lower in spirits. They also associated having radiotherapy with a worse prognosis.

The lower incidence of mood disturbance in the control group after they first saw the surgeons was related to what the surgeons said. Eighteen women were told they did not have cancer. Most of the other 32 women admitted for biopsy were given some hint that their disease was more likely to be benign. ${ }^{10}$ The inability of those who care for such patients to recognise and treat psychiatric symptoms is a serious problem and common in clinical practice.11:2 The surgeons were concerned about their patients, but had apparently failed to inquire explicitly about the women's emotional wellbeing. The women interpreted this as meaning that the surgeons were concerned only with their physical health.

The use of appropriately trained nurses, social workers, and volunteers to provide advice and monitor the emotional wellbeing of women before and after mastectomy might help to identify these emotional problems much earlier or even to reduce them. ${ }^{13-15}$

We thank all the surgeons who co-operated with us; Professor Michael Gelder and Professor George Brown for their help and guidance; and Dr Keith Durrant and Dr Jenny Collins, of the radiotherapy department. We especially thank the patients for their forebearance and understanding. This study was supported by the Cancer Research Campaign.

Copies of the psychiatric rating scales may be obtained from $\mathrm{Dr}$ G P Maguire.

\section{References}

1 Renneker, R, and Cutler, M, Fournal of the American Medical Association, $1962,148,833$.

'Q Quint, J, General Practitioner, 1964, 3, 119.

3 Torrie, A, World Medicine, 1971, 6, 36

${ }^{4}$ British Medical fournal, 1977, 1, 595.

${ }^{5}$ Brown, G W, et al, Psychological Medicine, 1973, 3, 74.

${ }^{6}$ Brown, G W, et al, British fournal of Psychiatry, 1977, 130, 1

' Morris, T, et al, Cancer. To be published.

${ }^{8}$ Devlin, B H, et al, British Medical fournal, 1971, 3, 413.

${ }^{9}$ Brown, G W, et al, Sociology, 1975, 9, 225.

11" Maguire, G P, et al. To be published.

${ }^{11}$ Goldberg, D P, and Blackwell, B, British Medical fournal, 1970, 2, 439.

12 Maguire, G P, et al, British Medical fournal, 1974, 1, 268.

${ }_{13}$ Dietz, J H, Medical Clinics of North America, 1969, 53, 607.

${ }^{14}$ Markels, W M, Cancer, 1971, 28, 1676.

15 Butler, A, Canadian Nurse, 1976, 72, No 6, 17.

(Accepted 13 fanuary 1978)

ONE HUNDRED YEARS AGO A very unusual case of accident came under my notice some time since in practice, and, as I have never seen or read of a similar one, perhaps it may be worthy of record. The case was one of injury of the eye, and happened as follows. One of the rests for supporting the globe of an ordinary gas-bracket entered the orbit of my patient, a young girl, pierced through the conjunctiva, and, being hooked or bent at the extremity, was entangled in one of the muscles at the external surface of the eyeball. This it tore from its attachment to the bone, and the belly of the muscle lay down the cheek when the girl came to me; the insertion of the muscle into the globe remaining intact. Of course, nothing could be done but cut the muscle as close to its insertion as possible; this was done, rest to the eye was enjoined, and evaporating lotions were applied to the orbit.

The muscle torn away must have been either the inferior oblique or the external rectus, as both are attached close together, at the outer aspect of the eyeball and near the cornea. From the structure of the muscle at its extremity, I should infer that it was the inferior oblique, as its origin was tendinous and by a single head, an arrangement very different from that obtaining in the case of external rectus, which arises by muscular fibres and is biventral. As the patient did not return, nothing could be gathered as to which muscle it was, from the loss of motion and strabismus which would inevitably result as a consequence of the destruction of the muscle. It may be assumed that no serious inflammatory action or loss of function resulted in the eye as a consequence of the injury; and this is rather surprising, as the force exerted must have been very considerable, and one would have expected that very serious consequences would have ensued to the delicate tissues of the eye. The very serious and unique character of the accident, and the minimum result of injury to the eyeball, have induced me to record this brief note of the case. (British Medical fournal, 1878.) 